\title{
Effect of meal fat quality on oxidation resistance of postprandial VLDL and LDL particles and plasma triacylglycerol level
}

\author{
Nina S. Nielsen ${ }^{1,2}$, Peter Marckmann ${ }^{2,3}$ and Carl-Erik Høy ${ }^{1,2}$ \\ ${ }^{1}$ Department of Biochemistry and Nutrition and ${ }^{2}$ Centre for Advanced Food Studies, The Technical University of Denmark, \\ Lyngby, Denmark \\ ${ }^{3}$ Research Department of Human Nutrition, The Royal Veterinary and Agricultural University, Copenhagen, Denmark
}

(Received 20 August 1999 - Revised 4 January 2000 - Accepted 14 February 2000)

\begin{abstract}
This study was performed to examine the postprandial effects of meals containing dietary fats, with their natural fatty acid composition and tocopherol content, on the plasma triacylglycerols (TG) and tocopherols and on the resistance of VLDL and LDL to oxidation. On six separate days eighteen healthy male subjects were given low-fat meals (LF) or the LF meals enriched with sunflower oil (SO), rapeseed oil (RO), olive oil (OO), palm oil (PO), or butter (B) in a crossover design. The fat-rich meals all resulted in similar postprandial TG responses while the LF test meal did not increase plasma TG level. The postprandial plasma fatty acid profile changed to resemble the fatty acid composition of the ingested test fat. The $\alpha$-tocopherol: $\gamma$ tocopherol ratios in postprandial plasma and VLDL samples were greater than in the test fats. We found that the resistance of VLDL particles to oxidation in the postprandial state as assessed from lag time was increased after the PO-rich meal as compared with the SO-rich meal $(P=$ $0 \cdot 018)$, and the propagation rate was greater after the SO- and RO-rich meals compared with the others $(P<0.001)$. The resistance of LDL particles to oxidation was unaffected by the meals. In postprandial VLDL samples, the content of $\alpha$-tocopherol was greater after the OO- and SO-rich meals compared with the meal rich in $\mathrm{PO}(P=0.034$ and 0.042 respectively). The $\gamma$-tocopherol content of VLDL was highest after RO-meal as compared with all other test meals $(P=$ $0.0019)$, and higher after SO as compared with B $(P=0.0148)$. Large individual differences were noted. In conclusion, meals enriched with different fats lead to the formation of VLDL particles with varying resistance to oxidation.
\end{abstract}

Dietary fat: Lipoproteins: Oxidation resistance: Polyunsaturated fatty acids

Atherosclerosis is a major cause of death in the Western countries. Recently, interest in risk markers has focused on the postprandial state, since during most of the day we are in the fed state, and not fasting. A high postprandial plasma triacylglycerol (TG) concentration is considered a risk marker of CHD (Patsch et al. 1992; Ebenbichler et al. 1995; Ginsberg et al. 1995). A diet rich in polyunsaturated fatty acids can reduce the postprandial TG response to fatty meals while diets rich in saturated fatty acids increase the response (Zampelas et al. 1994; Bergeron \& Havel, 1995).

Deposition of oxidatively-modified LDL in the intima is an important initial event in atherogenesis (Ylä-Herttuala et al. 1989; Beisiegel \& St Clair, 1996) and oxidised VLDL may also be involved (Ylä-Herttuala et al. 1988; Rapp et al. 1994; Hau et al. 1996). Some findings indicate that postprandial LDL particles are more easily oxidised than fasting LDL (Lechleitner et al. 1994). Similarly, postprandial VLDL particles may be more prone to oxidation than fasting VLDL. This could be partially due to elevated postprandial plasma TG resulting in competition for lipolysis between chylomicrons and VLDL. This again could result in increased plasma residence time of VLDL and thereby a greater risk of interaction with the cardiac wall. The fatty acid composition and antioxidant content of dietary fats is known to affect the oxidation resistance of the lipoprotein particles (Belcher et al. 1993; Reaven \& Witztum, 1993; Reaven et al. 1994). For these reasons, we decided to investigate the effect of dietary fats on the susceptibility of postprandial lipoproteins to oxidation and on the postprandial plasma TG level.

\footnotetext{
Abbreviations: B, butter; LF, low fat; OO, olive oil; PO, palm oil; RO, rapeseed oil; SO, sunflower oil; TG, triacylglycerol.

* Corresponding author: Dr Nina S. Nielsen, fax +4545886307, email ninas@mimer.be.dtu.dk
} 


\section{Subjects and methods}

\section{Subjects}

Eighteen healthy males were recruited for this study. Their average age was 27.2 (range $22-35$ ) years and their BMI was 22.2 (range $19.6-24.7$ ) $\mathrm{kg} / \mathrm{m}^{2}$. The subjects had plasma cholesterol, HDL-cholesterol and TG values within normal ranges (4.12 (range 3.04-6.12) mmol/l; 1.26 (range 0.762.07 ) $\mathrm{mmol} / \mathrm{l}$ and 0.91 (range $0.35-2.00$ ) $\mathrm{mmol} / \mathrm{l}$ respectively). Exclusion criteria were chronic diseases, recent donation of blood, regular intake of medication, dietary supplements and finally very high physical activity (maximum 1-2 $\mathrm{h}$ per week). The protocol was approved by the Ethical Committee of Frederiksberg and Copenhagen (jr. no. 01-272/95), and informed consent was obtained from the subjects according to the Second Helsinki Declaration.

Fasting plasma levels of TG, cholesterol and HDLcholesterol were determined on the day of each meal test. There were no statistical differences between the six meal test days.

\section{Study design}

The experiment was designed as a double-blinded randomized crossover study, in which the subjects participated in six different meal tests on separate days with at least 3 weeks between. The test meals were either low-fat meals or meals enriched with rapeseed oil (RO), olive oil (OO), sunflower oil (SO), palm oil (PO) or butter (B). On each test day two meals of varying size $(1.5$ and $5.7 \mathrm{MJ}$ respectively), but with identical macronutrient composition were served. Fat-rich test meals consisted of a low-fat basic rice dish ( $7 \%$ energy from fat) enriched with one of the test fats (to a total of $41 \%$ energy from fat, $10 \%$ from protein and $49 \%$ from carbohydrate, and including $2.8 \mathrm{~g}$ fibre/MJ). The low-fat test meals included banana and raisins as a replacement for the test fat to provide similar total energy content (7\% energy from fat, $12 \%$ from protein and $81 \%$ from carbohydrate, and including $4.0 \mathrm{~g}$ fibre/MJ). The basic rice dishes were made in one batch from rice, lean beef, onion, corn, red pepper and spices (salt, pepper, basil, thyme and curry powder). It was weighed into portions and frozen until use. Duplicate portions were chemically analysed for macronutrient composition.

The subjects were asked not to alter their physical activity during the study. The subjects were also instructed not to take any medication $14 \mathrm{~d}$ before a test and not to drink alcohol or perform hard physical activity $2 \mathrm{~d}$ before. On the evening before each test day they consumed a standardised meal (4.76 MJ, $21 \%$ energy from fat) not later than 20.00 hours after which time they were not allowed to eat anything and only to drink a maximum of 0.5 litres water after 22.00 hours.

The first meal was given on the test day between 09.00 and 09.30 hours and the second meal $1.75 \mathrm{~h}$ later between 10.45 and 11.15 hours. The design with two solid meals was chosen to simulate a normal situation of food intake where intake of the first may affect the postprandial response of the second. Blood samples were obtained in the fasting state, between the first and the second meal and every hour until $8.5 \mathrm{~h}$ after the first meal, and lipoproteins were isolated from samples obtained in the fasting state and $5.5 \mathrm{~h}$ after the first meal.

The test fats used in our study were a chemically refined SO (Solex W, Aarhus Olie A/S, Aarhus, Denmark), a virgin OO (Turri Bardolini, Carl Lange, Denmark), a physically refined RO (Department of Biotechnology, Technical University of Denmark, Lyngby, Denmark), a chemically refined PO (Palmotex EE, Aarhus Olie A/S) and B (MDFoods, Esbjerg, Denmark). The composition of the fats is displayed in Table 1. The fats all had a peroxide value of less than $0.5 \mathrm{meq} \mathrm{kg}$ fat and a free fatty acid content of less than $1 \mathrm{~g} / \mathrm{kg}$ fat.

Table 1. Fatty acid composition (mol/100 mol total fatty acids) and tocopherol content $(\mu \mathrm{g} / \mathrm{g}$ fat) of test fats

\begin{tabular}{|c|c|c|c|c|c|}
\hline Fatty acid & Sunflower oil & Rapeseed oil & Olive oil & Palm oil & Butter \\
\hline$<16: 0$ & 0.0 & 0.1 & 0.0 & 1.7 & $29 \cdot 1$ \\
\hline $16: 0$ & $6 \cdot 8$ & 4.8 & $15 \cdot 7$ & 33.9 & 31.6 \\
\hline $16: 1$ & 0.1 & 0.2 & $1 \cdot 8$ & 0.3 & $2 \cdot 2$ \\
\hline $18: 0$ & 4.1 & 1.8 & 2.5 & $3 \cdot 3$ & $10 \cdot 4$ \\
\hline $18: 1$ & $21 \cdot 1$ & 61.5 & $65 \cdot 6$ & $46 \cdot 4$ & 24.5 \\
\hline $18: 2 n-6$ & $66 \cdot 6$ & 26.4 & 13.2 & 13.7 & 1.4 \\
\hline $18: 3 n-3$ & 0.7 & 3.7 & 0.6 & 0.3 & 0.3 \\
\hline$>18: 0$ & 0.5 & 1.6 & 0.6 & 0.4 & 0.0 \\
\hline SFA & $11 \cdot 3$ & $6 \cdot 8$ & 18.5 & 39.2 & 69.9 \\
\hline MUFA & 21.4 & $62 \cdot 8$ & $67 \cdot 6$ & $46 \cdot \overline{8}$ & 27.9 \\
\hline PUFA & $67 \cdot 3$ & 30.4 & $13 \cdot 8$ & $14 \cdot 0$ & 1.7 \\
\hline$n-3$ PUFA & 0.7 & 3.7 & 0.6 & 0.3 & 0.3 \\
\hline$n-6$ PUFA & $66 \cdot 6$ & $26 \cdot 7$ & $13 \cdot 2$ & $13 \cdot 7$ & 1.4 \\
\hline Unsaturation index† & $156 \cdot 8$ & $127 \cdot 6$ & $95 \cdot 9$ & $75 \cdot 2$ & 31.5 \\
\hline$\alpha$-Tocopherolł & 254.1 & $112 \cdot 1$ & $38 \cdot 3$ & $67 . \overline{5}$ & $5 \cdot 1$ \\
\hline$\gamma$-Tocopherol & $31 \cdot 2$ & $142 \cdot 3$ & $13 \cdot 0$ & $16 \cdot 9$ & 1.5 \\
\hline
\end{tabular}

SFA, saturated fatty acids; MUFA, monounsaturated fatty acids; PUFA, polyunsaturated fatty acids.

$\dagger$ The unsaturation index is calculated as mol of a given polyunsaturated fatty acid/100 mol total fatty acids multiplied by the number of double bonds in that fatty acid; the values for all fatty acids are then summed.

$\ddagger$ Values are means of two determinations. No tocotrienols were detected in the test fats. 


\section{Methods}

Duplicate portions of the test meal (without the test oil) were chemically analysed. The fat content was measured after extraction according to the method of Folch et al. (1957), the protein content was measured according to the principle of Dumas (Kirsten \& Hesselius, 1983) and fibre content was determined enzymatically (Asp et al. 1983). The carbohydrate content was calculated by subtraction.

Blood from the subjects was collected in EDTAcontaining tubes $(47 \mu \mathrm{M})$, placed on ice and centrifuged at $3000 \mathrm{~g}$ for $15 \mathrm{~min}$ at $4^{\circ} \mathrm{C}$. Plasma was immediately isolated, and analysed or rapidly frozen in liquid $\mathrm{N}_{2}$ for later analysis. Sucrose was added to plasma for determination of lipoprotein oxidation resistance (final concentration $100 \mathrm{~g}$ sucrose/l plasma to avoid crystallisation during freezing) and frozen in liquid $\mathrm{N}_{2}$.

Plasma TG, total cholesterol and HDL-cholesterol concentrations were determined using commercial enzymatic methods (Boehringer-Mannheim GPO-PAP 701912 , B-M CHOD-PAP 236-691, and B-M 543-004 (for precipitation of chylomicrons, VLDL and LDL respectively); Boehringer Mannheim GmbH, Mannheim, Germany) on a Cobas Mira S analyser (Roche Diagnostic Systems, Basel, Switzerland).

\section{Fatty acid composition of test fats and plasma triacylglycerol}

One drop of test fat was dissolved in $10 \mathrm{ml}$ heptane. The sample was methylated with $60 \mu \mathrm{KOH}(2 \mathrm{M}$ in methanol) (Christopherson \& Glass, 1969). The upper phase was removed and the solvent (approximately $9 \mathrm{ml}$ ) evaporated. The sample was reconstituted in $1 \mathrm{ml}$ heptane and diluted $\times 50$ before analysis.

Plasma TG methyl esters were prepared from $200 \mu \mathrm{l}$ EDTA plasma samples. Lipids were extracted with methanol-chloroform $(1: 2, \mathrm{v} / \mathrm{v}) . \mathrm{NaCl}$ solution $(1 \mathrm{ml}$, $7 \cdot 3 \mathrm{~g} / \mathrm{l})$ was added and the sample centrifuged for $15 \mathrm{~min}$ at $4000 \mathrm{~g}$. The sample was further purified on a column with $\mathrm{Na}_{2} \mathrm{SO}_{4}$. Three-quarters $(1.5 \mathrm{ml})$ of the eluted $\mathrm{CHCl}_{3}$ extract was evaporated in a vacuum and reconstituted in $150 \mu \mathrm{l}$ chloroform-methanol $(95: 5, \mathrm{v} / \mathrm{v})$. The neutral lipids were separated on a TLC plate in heptane-2-propanolacetic acid (95:5:1, by vol.). The plate was sprayed with 2,7-dichlorofluorescein and spots were detected using u.v.light. The TG band was scraped off and extracted twice with $3 \times 1 \mathrm{ml}$ diethyl ether. The solvent was evaporated and the sample redissolved in $0.2 \mathrm{ml}$ hexane. The extract was then methylated with $\mathrm{KOH}$ (2 $\mathrm{M}$ in methanol). The solvent was evaporated and the sample reconstituted in $150 \mu \mathrm{l}$ heptane.

The fatty acid composition was determined by GLC of the methyl esters using an HP5880A GC (Hewlett-Packard, Ingelsheim, Germany) with a flame ionisation detector, a Supelco SP2380 column, $30 \mathrm{~m} \times 0.32 \mathrm{~mm}$ internal diameter fused silica (Supelco, Bellefonte, PA, USA). Temperatures were: injector $250^{\circ} \mathrm{C}$, detector $260^{\circ} \mathrm{C}$. The carrier gas was He. Aliquots of $5 \mu \mathrm{l}$ were injected using an autoinjector (HP 7673; Hewlett-Packard) with a flow of $12 \mathrm{ml} / \mathrm{min}$ and a split ratio of $1: 8 \cdot 3$. The column oven was temperature- programmed to a temperature of $120^{\circ} \mathrm{C}$ initially, raised by $4^{\circ} \mathrm{C} / \mathrm{min}$ to $160^{\circ} \mathrm{C}$, maintained for $2 \mathrm{~min}$, increased by $8^{\circ} \mathrm{C} /$ min to $200^{\circ} \mathrm{C}$, maintained for $10 \mathrm{~min}$, and finally increased by $30^{\circ} \mathrm{C} / \mathrm{min}$ to $225^{\circ} \mathrm{C}$. Fatty acids were identified by comparison with commercial standards (Nu-Check-Prep., Elysian, MN, USA) and quantified by the peak areas. Results were adjusted with predetermined response factors for the individual fatty acids and the composition weight $(\mathrm{g} /$ $100 \mathrm{~g}$ total fatty acids) was calculated. They were finally expressed as mol/100 mol total fatty acids by dividing the composition weight of each fatty acid by the molar weight of that fatty acid.

\section{Preparation and oxidation of VLDL and $L D L$}

The procedure for preparation and lipid peroxidation of lipoproteins has previously been described (Sørensen et al. 1998) with modifications in the method of isolation as follows. Briefly, $3 \mathrm{ml}$ plasma, which had been frozen and stored at $-80^{\circ} \mathrm{C}$ for no more that 12 months, was rapidly thawed and used for isolation of VLDL and LDL by ultracentrifugation at $285000 \mathrm{~g}$ and $4^{\circ} \mathrm{C}$. A gradient was constructed with solutions of decreasing density (1.21, $1.10,1.019$, and $1.0 \mathrm{~g} / \mathrm{cm}^{3} ; 2.6,3.0,2.0$, and $2.6 \mathrm{ml}$ respectively) consisting of $\mathrm{NaCl}$ and added EDTA $(10 \mu \mathrm{M})$. After $30 \mathrm{~min}$ the chylomicrons were isolated and the rest of the sample was ultracentrifuged for an additional $18 \mathrm{~h}$. The protein content was determined by the method of Lowry et al. (1951). The oxidation was initiated by adding $\mathrm{CuSO}_{4}$ to a final concentration of $40 \mu \mathrm{M}$.

The kinetics of the VLDL-LDL oxidation was followed by continuously monitoring the changes in absorbance at 234 nm (Esterbauer et al. 1989; Princen et al. 1992, 1995) with a thermostat-controlled spectrophotometer (set at $37^{\circ} \mathrm{C}$ ) and an automatic sample changer (UV-2101PC spectrophotometer, CPS controller and CPS-260 cell positioner; Shimadzu Scientific Instruments Inc., Columbia, MD, USA). From the reaction curve, the lag time and propagation rates of formation of conjugated dienes were determined. Lag time was determined by drawing a tangent to the steepest part of the curve and extrapolating to a tangent of the lag period (the horizontal part of the curve). The time from the addition of $\mathrm{Cu}^{2+}$ to the intersection equals the lag time and is expressed in min. The propagation rate is defined as the slope of the tangent of the propagation phase and is expressed as nmol dienes formed/min per $\mathrm{mg}$ LDL protein.

Absorbance curves of VLDL-LDL preparations obtained from each subject on each of the six occasions were determined in parallel. Each VLDL-LDL preparation was oxidised in three consecutive oxidation runs of $300 \mathrm{~min}$ within $24 \mathrm{~h}$; the values shown for lag time and propagation rate are means of the three values. In every oxidation run one reference VLDL-LDL sample, prepared from reference plasma stored at $-80^{\circ} \mathrm{C}$, was used as a control. Oxidation runs with $>10 \%$ deviation from the mean lag time or propagation rate of former measurements were omitted.

Using this standardised method it has been shown previously that there were no differences in lag times, propagation rates and maximum diene production between 
LDL prepared from plasma frozen in liquid $\mathrm{N}_{2}$ and from freshly collected plasma from the same subject. In addition, no differences in these variables were found following storage of plasma at $-80^{\circ} \mathrm{C}$ for up to 18 months (Princen et al. 1992, 1995; Hau et al. 1996; Brussaard et al. 1997).

The content of conjugated dienes was determined before and $5 \mathrm{~h}$ after initiation of oxidation by scanning the sample at $200-300 \mathrm{~nm}$. The difference in absorption between $234 \mathrm{~nm}$ and $242 \mathrm{~nm}$ of the second derivative of the spectrum indicates the content of cis, trans conjugated dienes and the difference between $242 \mathrm{~nm}$ and $252 \mathrm{~nm}$ indicates the content of trans, trans conjugated dienes (UVPC Spectroscopy Software, Shimadzu Scientific Instruments Inc.) (Corongui et al. 1994).

\section{Determination of tocopherol content}

Analysis of the tocopherol content was performed according to the method of Kaplan et al. (1990) on duplicate samples. The test fats were analysed using $42-43 \mathrm{mg}$ fat and $100 \mu \mathrm{l}$ internal standard (134 $\mu \mathrm{g} \alpha$-tocopherol acetate/ $\mathrm{ml})$. Plasma was analysed using $200 \mu \mathrm{l}$ sample and $100 \mu \mathrm{l}$ internal standard (10.165 $\mu \mathrm{g} \alpha$-tocopherol acetate $/ \mathrm{ml})$. For analysis of VLDL, 400-1000 $\mu \mathrm{l}$ VLDL fraction (0.15 mg protein $/ \mathrm{ml}$ ) was added to $200 \mu$ internal standard.

The entire extraction procedure was performed in darkness. The vitamins were extracted twice with $3 \mathrm{ml}$ hexane by mixing and centrifugation $(5 \mathrm{~min}, 2000 \mathrm{~g}$ at room temperature) (Hereaus megafuge 1.0; Hereaus, Oosterode am Harz, Germany) and the solvent $(6 \mathrm{ml})$ evaporated in a vacuum centrifuge (Christ Alpha RVC; Christ, Oosterode am Harz, Germany). The sample was reconstituted in $200 \mu \mathrm{l}$ acetonitrile-chloroform (80:20, v/ v) (HPLC-grade; Rathburn Chemicals Ltd, Walkerburn, Lothian, Scotland) and filtered (Chromafil, AO-45/3; Macherey-Nagel, Düren, Germany). The samples were analysed by HPLC using an on-line degasser (ERC-3415; ERC Inc, Tokyo, Japan), a pump (Waters 510; Waters Corporation, Milford, MA, USA), an autosampler (Water 717; Waters Corporation), a multiwavelength detector (Waters 490; Waters Corporation) and an LC-18 column $250 \times 4.6 \mathrm{~mm}$ with $5 \mu \mathrm{m}$ spherical particles (Supelco). The mobile phase consisted of acetonitrile-chloroform-2propanol-water (78:16:3.5:2.5, by vol.) (HPLC-grade; Rathburn Chemicals Ltd) and the flow rate was $2 \mathrm{ml} / \mathrm{min}$. The content of tocopherols was determined using u.v. detection at $292 \mathrm{~nm}$ by comparison with a commercial standard (Sigma, St Louis, MO, USA) using peak area for quantification.

\section{Statistics}

Results are expressed as means with standard errors of the means. Data were compared using one-way repeated measurement ANOVA (Jandel SigmaStat statistical Package, Version 2.0; Jandel Scientific Gmbh, Erkrath, Germany). When statistically significant effects were detected by ANOVA the results were compared by the Student-Newman-Keuls method. Correlations were tested by Pearsons correlation analysis. The level of statistical significance was set at $P<0.05$.

\section{Results \\ Plasma triacylglycerol level}

The fat-rich meals all resulted in similar postprandial TG responses with peak value about $4.5 \mathrm{~h}$ after the first meal and return to fasting levels $8.5 \mathrm{~h}$ after the first meal. The LF test meal did not increase plasma TG level and the TG level was significantly lower than the response to fat-rich test meals (Fig. 1) $(P<0 \cdot 0001)$.

The acute effects of the six meal tests applied in the present study on activation of blood coagulation factor VII have previously been presented by Larsen et al. (1997).

\section{Plasma triacylglycerol fatty acid profile}

The plasma TG fatty acid composition was determined in the fasting state and continuously during the day. At each test, the plasma fatty acid composition changed to resemble the fatty acid composition of the ingested test fat (data not shown). The fasting plasma samples showed no statistical difference in the saturated, monounsaturated or polyunsaturated fatty acids, 18:2 content, unsaturation index or 18:1:18:2 ratio (Table 2).

Following ingestion of the test fats at $5.5 \mathrm{~h}$, the orders of levels of saturated, monounsaturated and polyunsaturated fatty acids and of the unsaturation index in plasma TG were similar to the orders in the fats (Tables 2 and 3), e.g. the highest content of saturated fatty acid was found after B and the lowest after SO. The 18:1:18:2 ratio after eating test fats was highest after B followed by OO, PO, RO and LF, and $\mathrm{SO}$ in that order $(P<0.001)$ (Table 3).

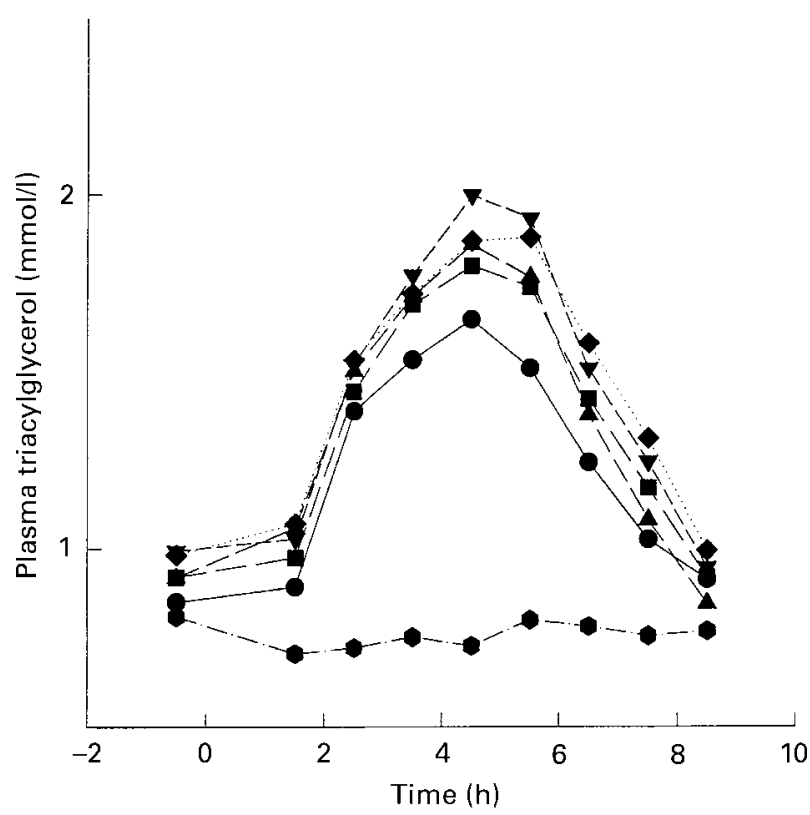

Fig. 1. Plasma triacylglycerol response in eighteen subjects following ingestion of two consecutive test meals at time 0 and $1.75 \mathrm{~h}$ enriched with either butter $(\boldsymbol{\bullet})$, rapeseed oil $(\boldsymbol{\square})$, olive oil $(\boldsymbol{\Lambda})$, palm oil $(\boldsymbol{\nabla})$, or sunflower oil $(\bullet)$ and after low-fat test meals $(\mathbf{\theta})$. For details of composition of test meals see p. 856; for fatty acid composition of test fats see Table 1. 
In the fasting state the VLDL particles had similar resistance to oxidation when considering lag time and propagation rate (Table 3$)$. In the postprandial state $(5.5 \mathrm{~h}$ after the first meal) we observed a longer lag time after intake of the PO-rich meal compared with the SO-rich meal $(P=0 \cdot 018)$. The propagation rate and the difference between postprandial and fasting propagation rate was higher after the SO- and RO-rich meals compared with the others (B, O, PO, LF) $(P<0.001)$. The amounts of cis, trans and trans, trans conjugated dienes formed during oxidation were similar no matter which test fat had been ingested both before the meals and postprandially (data not shown). The lag time was shorter following ingestion of the $\mathrm{SO}$ meals compared with fasting. Both SO and RO resulted in higher propagation rates compared with fasting whereas the $\mathrm{B}$ meals decreased the propagation rate.

\section{LDL oxidation resistance}

The oxidation resistances of LDL particles as determined by lag time and propagation rate were not different in the fasting state and were not affected by ingestion of different test meals (Table 3 ). In addition we observed no differences in lag time or propagation rate between fasting and postprandial state. As for the VLDL, the amounts of cis, trans and trans, trans conjugated dienes formed in LDL during oxidation were similar in all groups both before the meals and postprandially.

\section{Plasma tocopherol content}

Similar contents of both $\alpha$ - and $\gamma$-tocopherol in plasma samples were obtained in the fasting state (Table 4) on each meal test day. Postprandially $(5.5 \mathrm{~h})$, the content of $\gamma$ tocopherol was significantly higher after RO than after any of the other test meals $(P=0 \cdot 019)$. No differences in postprandial plasma contents of $\alpha$-tocopherol were found. Large inter-individual differences were observed.

\section{VLDL tocopherol content}

The content of $\alpha$ - and $\gamma$-tocopherol in VLDL in the fasting state (Table 4) was similar before the six meal tests. Postprandially (5.5 h after the first meal), the contents of $\alpha$ tocopherol were significantly higher after the OO- and SOrich meal compared with the meal rich in PO $(P=0.034$ and 0.042 respectively). The $\gamma$-tocopherol content of VLDL was highest after RO-meal compared with the level after the other test meals $(P=0 \cdot 002)$ and higher after SO compared with B $(P=0 \cdot 015)$. Large inter-individual differences were noted.

\section{Discussion}

In this present study we investigated the effect of fat quality on the susceptibility of VLDL and LDL to oxidation and the effect on plasma TG level in the postprandial phase using normal household dietary fats.

SO-rich meals resulted in a lag time in postprandial 
Table 3. Effect of two consecutive low-fat meals or the same meals enriched with sunflower oil, rapeseed oil, olive oil, palm oil or butter on the oxidation variables of VLDL and LDL in fasting and postprandial samples†

(Mean values with standard errors of the means for eighteen subjects)

\begin{tabular}{|c|c|c|c|c|c|c|c|c|c|c|c|c|}
\hline \multirow[t]{2}{*}{ Test fats... } & \multicolumn{2}{|c|}{ Sunflower oil } & \multicolumn{2}{|c|}{ Rapeseed oil } & \multicolumn{2}{|c|}{ Olive oil } & \multicolumn{2}{|c|}{ Palm oil } & \multicolumn{2}{|c|}{ Butter } & \multicolumn{2}{|c|}{ Low fat } \\
\hline & Mean & SEM & Mean & SEM & Mean & SEM & Mean & SEM & Mean & SEM & Mean & SEM \\
\hline \multicolumn{13}{|l|}{ VLDL } \\
\hline $\mathrm{F}$, laq timeł & $140 \cdot 6$ & 14.4 & 144.7 & 13.5 & $125 \cdot 5$ & 10.9 & 148.5 & $9 \cdot 0$ & 142.5 & 11.6 & $150 \cdot 9$ & 13.7 \\
\hline PP, lag time & $106 \cdot 5^{\mathrm{a}^{*}}$ & $9 \cdot 1$ & $134 \cdot 2$ & $10 \cdot 0$ & $128 \cdot 1$ & $10 \cdot 9$ & $167 \cdot 2^{\mathrm{b}}$ & 14.0 & 148.5 & $10 \cdot 4$ & $136 \cdot 7$ & 9.2 \\
\hline $\mathrm{F}$, prop rate§ & 23.5 & $2 \cdot 2$ & 23.7 & $2 \cdot 6$ & $25 \cdot 4$ & 1.5 & $21 \cdot 8$ & $2 \cdot 1$ & 23.0 & 1.8 & $26 \cdot 6$ & $2 \cdot 2$ \\
\hline PP, prop rate§ & $39 \cdot 8^{a^{*}}$ & $5 \cdot 7$ & $33 \cdot 4^{\mathrm{a}^{\star}}$ & $4 \cdot 4$ & $20 \cdot 9^{b}$ & 2.9 & $21 \cdot 7^{b}$ & $2 \cdot 4$ & $15 \cdot 6^{b^{*}}$ & $1 \cdot 3$ & $24 \cdot 4^{b}$ & $2 \cdot 7$ \\
\hline \multicolumn{13}{|l|}{ LDL } \\
\hline $\mathrm{F}$, lag time & $79 \cdot 3$ & $3 \cdot 0$ & $78 \cdot 8$ & 4.8 & $76 \cdot 3$ & 3.6 & $78 \cdot 8$ & 4.9 & $86 \cdot 7$ & $10 \cdot 6$ & $73 \cdot 3$ & $3 \cdot 0$ \\
\hline PP, lag time & $76 \cdot 7$ & $5 \cdot 1$ & $75 \cdot 2$ & 3.6 & 77.0 & 4.1 & $75 \cdot 1$ & $7 \cdot 8$ & $82 \cdot 8$ & 4.6 & $76 \cdot 9$ & $2 \cdot 0$ \\
\hline $\mathrm{F}$, prop rate§ & $13 \cdot 2$ & 1.0 & $12 \cdot 7$ & 0.9 & $13 \cdot 9$ & 0.6 & $12 \cdot 7$ & 0.6 & $12 \cdot 3$ & 1.0 & 14.9 & 0.8 \\
\hline PP, prop rate§ & $14 \cdot 8$ & 0.9 & $13 \cdot 4$ & 0.6 & $13 \cdot 6$ & $0 \cdot 6$ & $12 \cdot 9$ & 0.6 & $13 \cdot 4$ & $0 \cdot 8$ & $14 \cdot 2$ & 0.7 \\
\hline
\end{tabular}

F, fasting samples; PP, postprandial samples; prop rate, propagation rate.

a,b Mean values within a row with unlike superscript letters were significantly different $(P<0.001)$

Mean values were significantly different from the corresponding fasting values: ${ }^{*} P<0.001$.

† Postprandial samples were taken $5.5 \mathrm{~h}$ after the first meal. For details of the meals see p. 856 and Table 1 . The low-fat meals were the basic rice dish $(7 \%$ energy from fat) without any added test fat.

$\ddagger$ Lag time expressed as $\min ^{-1}$.

$\S$ Propagation rate expressed as $\mathrm{nmol} / \mathrm{mg}$ per $\mathrm{min}$.

VLDL particles that was significantly shorter compared with PO but not with B. After the SO-rich meals, the plasma unsaturation index was the highest $(P<0.001)$ and the 18:1:18:2 ratio the lowest $(P<0 \cdot 001)$. Postprandial plasma TG reflected the fatty acid composition of the test fats. The fatty acid composition of plasma TG was measured $3.75 \mathrm{~h}$ after the second meal. Since chylomicrons are cleared fast (Havel, 1997), within $6 \mathrm{~h}$ (Sethi et al. 1993), plasma TG resembles the fatty acid composition of VLDL. We found an inverse correlation between VLDL lag time and plasma unsaturation index $\left(R^{2} 0.61\right)$. This is supported by diet studies demonstrating a relationship between lag time and unsaturated diets or fatty acids in lipoproteins (Kleinveld et al. 1993; Reaven et al. 1994; Turpeinen et al. 1995). However, the fact that B resulted in the lowest unsaturation index but did not result in a lag time significantly different from SO indicates the presence of an additional factor, e.g. the content of antioxidants, that may influence lag time. In several supplementation studies (Dieber-Rotheneder et al. 1991; Princen et al. 1992; Reaven \& Witztum, 1993; Winklerhofer-Roob et al. 1995) a positive relationship between $\alpha$-tocopherol content and lag time has been demonstrated. When diets with their natural content of tocopherol were given, no correlations between lag time and $\alpha$-tocopherol content were observed (Kleinveld et al. 1993; Mata et al. 1997). We found a negative correlation between VLDL lag time and VLDL $\alpha$ tocopherol content $\left(R^{2} 0 \cdot 85\right)$. Thus, the positive correlation between lag time and tocopherol content may only be present when $\alpha$-tocopherol is present in higher concentrations in the lipoprotein than normally obtained through a varied diet without supplementation. In addition it was demonstrated that during supplementation only $50 \%$ of the oxidation resistance is mediated by $\alpha$-tocopherol (DieberRotheneder et al. 1991).

The $\alpha$-tocopherol content of the SO was much greater than that of the other fats. Nevertheless, the highest plasma content postprandially was observed after ingestion of the RO meal (NS). The high polyunsaturated fatty acid content of SO apparently reduces the total $\alpha$-tocopherol in plasma presumably due to antioxidant activity (Tribble et al. 1995; Visioli et al. 1995). Traber \& Kayden (1989) indicated that the liver discriminates between the tocopherols: $\gamma$ tocopherol is preferentially secreted to the bile, whereas $\alpha$-tocopherol is incorporated into VLDL. They gave supplements of $1000 \mathrm{mg}$ of both $\alpha$ - and $\gamma$-tocopherol,

Table 4. Effect of two consecutive low-fat meals or the same meals enriched with sunflower oil, rapeseed oil, olive oil, palm oil or butter on the $\alpha$ and $\gamma$-tocopherol content of plasma and VLDL in fasting and postprandial samples ${ }^{*} \dagger$

(Mean values with standard errors of the means for eighteen subjects)

\begin{tabular}{|c|c|c|c|c|c|c|c|c|c|c|c|c|c|c|}
\hline & \multicolumn{2}{|c|}{ Fasting $\dagger$} & \multicolumn{2}{|c|}{ Sunflower oil } & \multicolumn{2}{|c|}{ Rapeseed oil } & \multicolumn{2}{|c|}{ Olive oil } & \multicolumn{2}{|c|}{ Palm oil } & \multicolumn{2}{|c|}{ Butter } & \multicolumn{2}{|c|}{ Low fat } \\
\hline & Mean & $\overline{\text { SEM }}$ & Mean & $\overline{\text { SEM }}$ & Mean & $\overline{\text { SEM }}$ & Mean & $\overline{\text { SEM }}$ & Mean & $\overline{\text { SEM }}$ & Mean & $\overline{\text { SEM }}$ & Mean & $\overline{\text { SEM }}$ \\
\hline Plasma $\alpha$-tocopherol ( $\mu \mathrm{g} / \mathrm{ml})$ & $25 \cdot 3$ & 4.68 & $31 \cdot 29$ & $5 \cdot 37$ & $31 \cdot 81$ & $7 \cdot 34$ & $27 \cdot 51$ & $6 \cdot 81$ & $29 \cdot 24$ & 1.5 & 24.93 & 3.73 & $26 \cdot 33$ & $7 \cdot 86$ \\
\hline Plasma $\gamma$-tocopherol $(\mu \mathrm{g} / \mathrm{ml})$ & 1.71 & 0.48 & $2.58^{\mathrm{b}}$ & 0.45 & $5 \cdot 74^{a}$ & 1.43 & $1.77^{\mathrm{b}}$ & 0.22 & $1.97^{\mathrm{b}}$ & 0.37 & $1 \cdot 81^{b}$ & 0.23 & $1.09^{b}$ & 0.31 \\
\hline VLDL $\alpha$-tocopherol ( $\mu \mathrm{g} / \mathrm{mg}$ VLDL protein) & $5 \cdot 32$ & 0.86 & $6 \cdot 54^{\mathrm{a}}$ & 1.03 & $5 \cdot 23$ & 0.49 & $6 \cdot 16^{a}$ & 0.83 & $3.91^{\mathrm{b}}$ & 0.63 & 5.49 & 0.6 & $5 \cdot 51$ & 0.81 \\
\hline VLDL $\gamma$-tocopherol ( $\mu \mathrm{g} / \mathrm{mg}$ VLDL protein) & 0.3 & 0.07 & $0.51^{\mathrm{b}}$ & 0.09 & $0.91^{\mathrm{a}}$ & $0 \cdot 16$ & $0.34^{b}$ & 0.08 & $0.35^{\mathrm{b}}$ & 0.13 & $0.26^{b}$ & 0.04 & $0.28^{b}$ & 0.08 \\
\hline
\end{tabular}

${ }^{\mathrm{a}, \mathrm{b}}$ Mean values within a row with unlike superscript letters were significantly different $(P<0.05)$.

* Postprandial samples were taken $5.5 \mathrm{~h}$ after the first meal. For details of the meals see p. 856 and Table 1 . The low-fat meals were the basic rice dish $(7 \%$ energy from fat) without any test fat.

† No tocotrienols were detected in the test fats or plasma samples.

¥ Fasting values are the mean values from all test occasions. No significant differences were found between the fasting values for each test fat. 
(a)

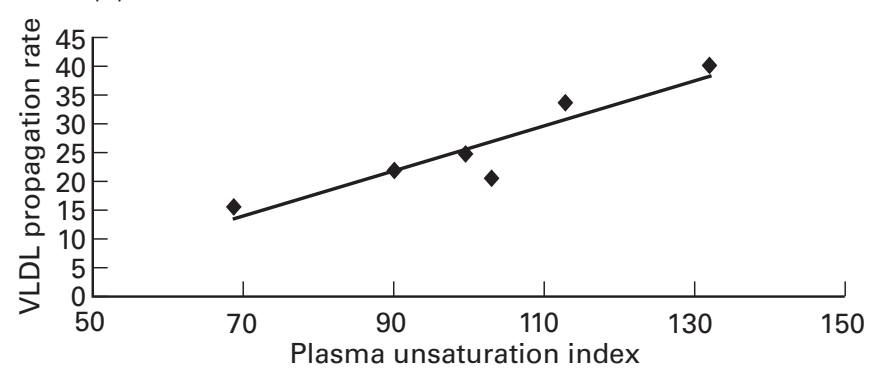

(b)

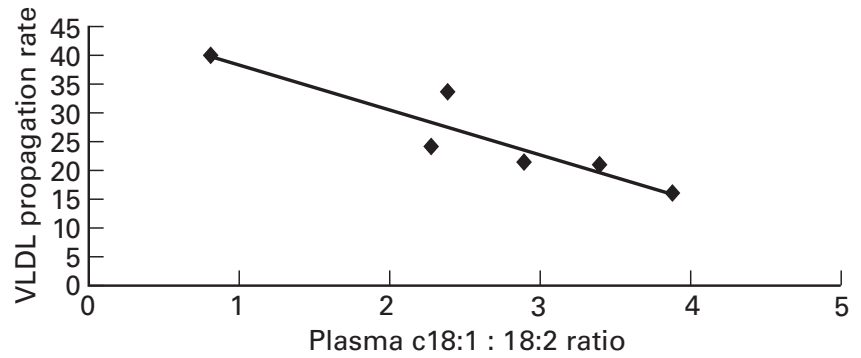

Fig. 2. Correlations between VLDL propagation rate during oxidation and (a) plasma triacylglycerol unsaturation index $\left(R^{2} 0.872\right)$ and (b) plasma triacylglycerol ratio of oleic acid to linoleic acid $\left(R^{2} 0.863\right)$ in samples obtained in the postprandial state $5.5 \mathrm{~h}$ after the first meal. For details of test meals see p. 856 and of fatty acid composition of test fats see Table 2. Values are means for all subjects $(n 18)$. The unsaturation index is calculated as mol of a given polyunsaturated fatty acid/100 mol total fatty acids multiplied by the number of double bonds in that fatty acid; the values for all fatty acids are then summed.

much higher than amounts normally consumed. Since the efficiency of absorption decreases with increasing amounts of tocopherol (Losowsky et al. 1972) the absorption may not be optimal when large amounts are given. We found greater $\alpha$-tocopherol: $\gamma$-tocopherol ratio in plasma compared with the ratio in the meals but a similar ratio in VLDL compared with the ratio in plasma. Another study (Meydani et al. 1989) in which supplements of $\alpha$ - and $\gamma$ tocopherol were given (approximately $20 \mathrm{mg} \alpha$-tocopherol $+60 \mathrm{mg} \gamma$-tocopherol in one experiment, and 25-30 mg of each in another) only demonstrated an increase in plasma $\gamma$-tocopherol. These results indicate differences in absorption rather than discrimination by the liver.

The intake of different types of fat greatly affected the fatty acid composition of postprandial plasma (mainly VLDL particles) and the propagation rate of oxidation. The unsaturation index of plasma fatty acids was similar to unsaturation index of the fats and the propagation rate correlated positively with the unsaturation index and negatively with the $18: 1: 18: 2$ ratio $\left(R^{2} \quad 0.87\right.$ and 0.86 respectively) (Fig. 2(a) and (b)). This is consistent with results observed in LDL after dietary intervention (Turpeinen et al. 1995; O'Byrne et al. 1998).

The high amount of test fat added to the very-LF basic rice dish resulted in a high contribution of test fat fatty acids to the total fat content. On a normal diet the changes observed here may not be as pronounced, due to the lower amount of added oil or butter and higher content of fat from other ingredients.

No difference in the susceptibility of postprandial LDL particles to oxidation was observed following ingestion of the different test fats. Neither was a difference expected, due to the relatively slow turnover of LDL (d). However, Lechleitner et al. (1994) have observed that postprandial LDL particles may be more easily oxidised than fasting LDL particles as indicated by a more pronounced cholesterol ester accumulation in cells and a higher content of thiobarbituric acid-reacting substances after incubation with $\mathrm{CuSO}_{4}$ or cells. They suggested that the reason for the increased atherogenicity could be a greater susceptibility to oxidation. However, we did not find any differences in the resistance to oxidation between the fasting and postprandial LDL samples after any of the test meals. In this present study, the transfer of fatty acids and vitamins between the lipoproteins in plasma, as suggested by Granot et al. (1988) and Meydani et al. (1989), apparently did not occur to a degree great enough to result in changes in the resistance of the LDL particles to oxidation within the timescale examined. It is possible that the use of a liquid test meal in the study by Lechleitner et al. (1994) resulted in a shorter passage time through the stomach and thereby a faster absorption and transfer to LDL, since they observed a change in LDL of more than $50 \%$ maximal change only $2 \mathrm{~h}$ after intake of the meal.

We observed that VLDL particles became more susceptible to oxidation after ingestion of polyunsaturated fatty acid-rich meals and less after saturated fatty acid-rich meals in agreement with a turnover rate of VLDL in the order of $\mathrm{h}$.

The in vitro results are not directly comparable with the 
in vivo situation in plasma where the lipoproteins are in contact with water-soluble antioxidants and in the intima of the vessel wall.

Schrezenmeir et al. (1992) demonstrated that an exaggerated postprandial TG response may increase the atherogenic risk even in healthy subjects with normal fasting TG levels. Others have demonstrated a relationship between postprandial TG and atherosclerosis (Ginsberg et al. 1995). Postprandial TG has even been shown to be an independent predictor of CHD (Patsch et al. 1992). We found no effect on plasma TG level between any of the fatrich meals given in this study, but a significantly lower lipaemic response after the low-fat meal compared with the fat-rich meals (Fig. 1). A linear relationship between meal fat content and postprandial TG response was demonstrated by Cohen et al. (1988). Thus, it may be beneficial to lower the meal fat content also in snacks and in-between meals in order to lower plasma TG level and thereby the residence time of circulating lipoprotein particles.

In conclusion, meals enriched in SO (with a very high polyunsaturated:saturated ratio) led to formation of postprandial VLDL particles that seemed to be more prone to oxidation in vitro compared with $\mathrm{RO}, \mathrm{OO}, \mathrm{PO}$ and $\mathrm{B}$. There was no effect of the different fat sources on plasma TG concentration, but a much lower TG response following low-fat meals.

\section{Acknowledgements}

Kirsten Nielsen gave technical assistance with determinations of fatty acid compositions and vitamin contents and Kirsten Bryde and Klara Jørgensen gave other technical assistance. Financial support was provided by the Danish Food Technology Research Program (FØTEK 2).

\section{References}

Asp KG, Johansson CG, Hallmer H \& Siljeström M (1983) Rapid enzymatic assay of insoluble and soluble dietary fiber. Journal of Agricultural Food Chemistry 31, 876-882.

Beisiegel U \& St Clair RW (1996) An emerging understanding of the interactions of plasma lipoproteins with the arterial wall that leads to the development of atherosclerosis. Current Opinion in Lipidology 7, 265-268.

Belcher JD, Balla J, Balla G, Jacobs DR, Gross M, Jacob HS \& Vercellotti GM (1993) Vitamin E, LDL, and endothelium. Brief oral vitamin supplementation prevents oxidized LDL-mediated vascular injury in vitro. Arteriosclerosis and Thrombosis 13, 1779-1789.

Bergeron N \& Havel RC (1995) Influence of diets rich in saturated and omega- 6 polyunsaturated fatty acids on the postprandial responses of apolipoproteins B-48, B-100, E, and lipids in triglyceride-rich lipoproteins. Arteriosclerosis, Thrombosis and Vascular Biology 15, 2111-2121.

Brussaard HE, Leuven JAG, Kluft C, Krans MJ, Duyvenvoorde W, Buytenhek R, Van der Laarse A \& Princen HMG (1997) Effect of $17 \beta$-estradiol on plasma lipids and LDL oxidation in postmenopausal women with type II diabetes mellitus. Arteriosclerosis, Thrombosis and Vascular Biology 17, 324-330.

Christopherson SW \& Glass RL (1969) Preparation of milk fat methyl esters by alcoholysis in an essential nonalcoholic solution. Journal of Dairy Science 52, 1289-1290.

Cohen JC, Noakes TD \& Benade AJS (1988) Serum triglyceride responses to fatty meals: effects of meal fat content. American Journal of Clinical Nutrition 47, 825-827.

Corongiu FP, Banni S \& Lombardi B (1994) Quantitation of conjugated dienes by second-derivative UV-spectroscopy. Methods in Toxicology 1B, 415-420.

Dieber-Rotheneder M, Puhl H, Waeg G, Striegl G \& Esterbauer H (1991) Effect of oral supplementation with D- $\alpha$-tocopherol on the vitamin E content of human low density lipoproteins and resistance to oxidation. Journal of Lipid Research 32, 13251332.

Ebenbichler CF, Kirchmair R, Egger C \& Patch JR (1995) Postprandial state and atherosclerosis. Current Opinion in Lipidology 6, 286-290.

Esterbauer H, Striegl G, Puhl H \& Rotheneder M (1989) Continuous monitoring of in vitro oxidation of human low density lipoprotein. Free Radical Research Communication 6, 67-75.

Folch J, Lees M \& Stanley GHS (1957) A simple method for the isolation and purification of total lipides from animal tissues. Journal of Biological Chemistry 226, 497-509.

Ginsberg HN, Jones J, Blaner WS, Thomas A, Karmally W, Fields L, Blood D \& Begg MD (1995) Association of postprandial triglyceride and retinyl palmitate responses with newly diagnosed exercise-induced myocardial ischemia in middle-aged men and women. Arteriosclerosis, Thrombosis and Vascular Biology 15, 1829-1838.

Granot E, Tamir I \& Deckelbaum RJ (1988) Neutral lipid transfer protein does not regulate $\alpha$-tocopherol transfer between human plasma lipoproteins. Lipids 23, 17-21.

Hau M-F, Smelt AHM, Bindels AJGH, Sijbrands EJG, Van der Laarse A, Onkenhout W, van Duyvenvoorde W \& Princen HMG (1996) Effects of fish oil on oxidation resistance of VLDL in hypertriglyceridemic patients. Arteriosclerosis, Thrombosis and Vascular Biology 16, 1197-1202.

Havel RC (1997) Postprandial lipid metabolism: an overview. Proceedings of the Nutrition Society 56, 659-666.

Kaplan LA, Miller JA, Stein EA \& Stampfer MJ (1990) Simultaneous, high-performance liquid chromatographic analysis of retinol tocopherols lycopene, and $\alpha$ - and $\beta$-carotene in serum and plasma. Methods in Enzymology 189, 155-167.

Kirsten WJ \& Hesselius GU (1983) Rapid, automatic, high capacity Dumas determination of nitrogen. Microchemical Journal 28, 529-547.

Kleinveld HA, Naber AHJ, Stalenhoef AFH \& Demacker PNM (1993) Oxidation resistance, oxidation rate, and extent of oxidation of human low density lipoprotein depend on the ratio of oleic acid content to linoleic acid content: studies in vitamin E deficient subjects. Free Radical Biology \& Medicine 15, 273-280.

Larsen LF, Bladbjerg E-M, Jespersen J \& Marckmann P (1997) Effects of dietary fat quality and quantity on postprandial activation of blood coagulation factor VII. Arteriosclerosis, Thrombosis and Vascular Biology 17, 2904-2909.

Lechleitner M, Hoppichler F, Föger B \& Patsch JR (1994) Lowdensity lipoproteins of the postprandial state induce cellular cholesteryl ester accumulation in macrophages. Arteriosclerosis and Thrombosis 14, 1799-1807.

Losowsky MS, Kelleher J, Walker BE, Davies T \& Smith CL (1972) Intake and absorption of tocopherol. Annals of the New York Academy of Sciences 203, 212-222.

Lowry OH, Rosebrough NJ, Farr AL \& Randall RJ (1951) Protein measurement with the Folin phenol reagent. Journal of Biological Chemistry 193, 265-275.

Mata P, Varela O, Alonso R, Lahoz C, de Oya M \& Badimon L (1997) Monounsaturated and polyunsaturated $n-6$ fatty acidenriched diets modify LDL oxidation and decrease human 
coronary smooth muscle cell DNS synthesis. Arteriosclerosis, Thrombosis and Vascular Biology 17, 2088-2095.

Meydani M, Cohn JS, Macauley JB, McNamara JR, Blumberg JB \& Schaefer EJ (1989) Postprandial changes in the plasma concentration of $\alpha$ - and $\gamma$-tocopherol in human subjects fed a fat-rich meal supplemented with fat-soluble vitamins. Journal of Nutrition 119, 1252-1258.

O'Byrne DJ, O'Keefe SF \& Shireman RB (1998) Low-fat, monounsaturated-rich diets reduce susceptibility of low density lipoproteins to peroxidation ex vivo. Lipids 33, 149-157.

Patsch JR, Miesenböck G, Hopferwieser T, Mühlberger V, Knapp E, Dunn JK, Gotto AM \& Patch W (1992) Relation of triglyceride metabolism and coronary artery disease. Studies in the postprandial state. Arteriosclerosis and Thrombosis 12, 1336-1345.

Princen HMG, Poppel VG, Vogelezang C, Buytenhek R \& Kok FJ (1992) Supplementation with vitamin $E$ but not $\beta$-carotene in vivo protects low density lipoprotein from lipid peroxidation in vitro. Effect of cigarette smoking. Arteriosclerosis and Thrombosis 12, 554-562.

Princen HMG, van Duyvenvoorde W, Buytenhek R, Van der Laarse A, van Poppel G, Leuven JAG \& van Hinsberg VWM (1995) Supplementation with low doses of vitamin E protects LDL from lipid peroxidation in men and women. Arteriosclerosis, Thrombosis and Vascular Biology 15, 325-333.

Rapp JH, Lespine A, Hamilton RL, Colyvas N, Chaumeton AH, Tweedie-Hardman J, Kotite L, Kunitake ST, Havel RJ \& Kane JP (1994) Triglyceride-rich lipoproteins isolated by selected-affinity anti-apolipoprotein B immunosorption from human atherosclerotic plaque. Arteriosclerosis and Thrombosis 14, 1767-1774.

Reaven PD, Grasse BJ \& Tribble DL (1994) Effects of linoleateenriched and oleate-enriched diets in combination with $\alpha$ tocopherol on the susceptibility of LDL and LDL subfractions to oxidative modification in humans. Arteriosclerosis and Thrombosis 14, 557-566.

Reaven PD \& Witztum JL (1993) Comparison of supplementation of RRR- $\alpha$-tocopherol and racemic $\alpha$-tocopherol in humans. Effects on lipid levels and lipoprotein susceptibility to oxidation. Arteriosclerosis and Thrombosis 13, 601-608.

Schrezenmeir J, Weber P, Probst R, Biesalski HK, Luley C, Prellwitz W, Krause U \& Beyer J (1992) Postprandial pattern of triglyceride rich lipoprotein in normal-weight humans after an oral lipid load: exaggerated triglycerides and altered insulin response in some subjects. Annals of Nutrition and Metabolism 36, 186-196.

Sethi S, Gibney MJ \& Williams CM (1993) Postprandial lipoprotein metabolism. Nutrition Research Reviews 6, 161-183.

Sørensen NS, Marckmann P, Høy C-E, Duyvenvoorde W \& Princen HMG (1998) Effect of fish-oil-enriched margarine on plasma lipids, low-density-lipoprotein particle composition, size, and susceptibility to oxidation. American Journal of Clinical Nutrition 68, 235-241.

Traber MG \& Kayden HJ (1989) Preferential incorporation of $\alpha$ tocopherol vs $\gamma$-tocopherol in human lipoproteins. American Journal of Clinical Nutrition 49, 517-526.

Tribble DL, Thiel PM, van den Berg JJM \& Krauss RM (1995) Differing $\alpha$-tocopherol oxidative lability and ascorbic acid sparing effects in buoyant and dense LDL. Arteriosclerosis, Thrombosis and Vascular Biology 15, 2025-2031.

Turpeinen AM, Alfthan G, Valsta L, Hietanen E, Salonen JT, Schunk H, Nyyssönen K \& Mutanen M (1995) Plasma and lipoprotein lipid peroxidation in humans on sunflower and rapeseed oil diets. Lipids 30, 485-492.

Visioli F, Bellomo G, Montedoro G \& Galli C (1995) Low density lipoprotein oxidation is inhibited in vitro by olive oil constituents. Atherosclerosis 117, 25-32.

Winklerhofer-Roob BM, Ziouzenkova O, Puhl H, Ellenmunter $\mathrm{H}$, Greiner P, Müller G, van't Hof MA, Esterbauer H \& Shmerling DH (1995) Impaired resistance to oxidation of low density lipoprotein in cystic fibrosis: improvement during vitamin E supplementation. Free Radical Biology \& Medicine 19, 725-733.

Ylä-Herttuala S, Jaakkola O, Ehnholm C, Tikkanen MJ, Solakivi T, Särkioja T \& Nikkari T (1988) Characterization of two lipoproteins containing apolipoproteins B and E from lesion-free human aortic intima. Journal of Lipid Research $\mathbf{2 9}$, 563-572.

Ylä-Herttuala S, Palinsky W, Rosenfeld ME, Parthasarathy S, Carew TE, Butler SW, Witztum JL \& Steinberg D (1989) Evidence for the presence of oxidatively modified low density lipoprotein in atherosclerotic lesions of rabbit and man. Journal of Clinical Investigation 84, 1086-1095.

Zampelas A, Peel AS, Gould BJ, Wright J \& Williams CM (1994) Polyunsaturated fatty acids of the $n-6$ and $n-3$ series: effects on postprandial lipid and apolipoprotein levels in healthy men. European Journal of Clinical Nutrition 48, 842-848. 